\title{
Cutaneous CD8+ Cytotoxic T-Cell Lymphoma Infiltrates: Clinicopathological Correlation and Outcome of 35 Cases
}

\author{
Marion Wobser • Theresa Reinartz · Sabine Roth • Matthias Goebeler • \\ Andreas Rosenwald · Eva Geissinger
}

Received: May 9, 2016 / Published online: August 18, 2016

(C) The Author(s) 2016. This article is published with open access at Springerlink.com

ABSTRACT
Introduction: Cytotoxic $\quad$ CD8+ T-cell lymphomas are only rarely encountered and thus remain only poorly characterized. Our aim was to collect and correlate clinical and histological data of CD8+ skin lymphoma infiltrates to obtain a proper subtype assignment of CD8+ skin lymphoma infiltrates and to derive putative prognostic markers thereof.

Methods: Formalin-fixed

and paraffin-embedded (FFPE) tissue of 35 patients with CD8+ cytotoxic cutaneous T-cell lymphoma infiltrates was retrieved from the archives of the Institute of Pathology and the Department of Dermatology, University Hospital Wuerzburg, dating back from 1998

Enhanced content To view enhanced content for this article go to http://www.medengine.com/Redeem/ A4E4F0600276E635.

M. Wobser $(\bowtie) \cdot$ T. Reinartz · M. Goebeler

Department of Dermatology, University Hospital Würzburg, Würzburg, Germany

e-mail: Wobser_M@ukw.de

\section{S. Roth · A. Rosenwald · E. Geissinger}

Institute of Pathology and Comprehensive Cancer

Center Mainfranken, University of Würzburg,

Würzburg, Germany until 2015. Cytological, histological, immunohistochemical and molecular genetic features were assessed and correlated with respective clinical data.

Results: The identified cases of CD8+ cytotoxic atypical lymphoproliferative infiltrates of the skin $(n=35)$ comprised 13 cases of mycosis fungoides (MF)/Sézary syndrome (SS), 4 cases of subcutaneous panniculitis-like T-cell lymphoma (SPTCL), 5 cases of primary cutaneous acral CD8+ lymphoma [formerly indolent CD8+ lymphoid proliferation (ILP)] and 1 case of aggressive epidermotropic primary cutaneous T-cell lymphoma (AECTCL). Moreover, nine cases were classified as primary cutaneous peripheral T-cell lymphoma, not otherwise specified (PTCL-NOS) and three cases as systemic PTCL-NOS. Multiple skin lesions, a high proliferative index and especially a final subtype attribution to AECTCL or systemic PTCL-NOS were associated with a worse survival. Coexpression of CD68 by tumor cells was exclusively observed in indolent acral CD8+ T-cell lymphoma and thus indicated an invariably benign clinical course. No further distinctive markers could be derived from our analysis. 
Conclusion: Cutaneous infiltrates of CD8+ cytotoxic T-cell lymphoma comprise clinically and histologically heterogeneous entities of either primary cutaneous T-cell lymphomas or secondary infiltrates of otherwise systemic peripheral T-cell lymphomas. A thorough clinicopathological correlation with respective staging examinations remains the mainstay for correct subtype assignment and proper prognostication as long as no better markers have been defined.

Keywords: Cutaneous lymphomas; Cytotoxic; Histology; Prognosis

\section{INTRODUCTION}

Primary cutaneous T-cell lymphomas comprise heterogeneous entities with diverse histological, phenotypic and molecular genetic features dependent on the respective cell of origin [1]. Most T-cell lymphomas of the skin exhibit a skin-homing CD4+ T-helper cell phenotype. CD8+ cutaneous lymphomas usually represent rare CD8+ variants of otherwise common and well-characterized CD4+ lymphomas, such as CD8+ variants of mycosis fungoides (MF) and Sézary syndrome (SS), CD30+ lymphoproliferative disorders, subcutaneous panniculitis-like T-cell lymphoma (SPTCL) or peripheral T-cell lymphoma, not otherwise specified (PTCL-NOS) [2]. In contrast, an exclusive $\mathrm{CD} 8+$ phenotype is present in the eponymous CD8+ acral T-cell lymphoma [3] formally known as CD8+ indolent lymphoid proliferation (ILP) [4] as well as in aggressive epidermotropic cutaneous T-cell lymphoma (AECTCL) [5].

Such rare CD8+ cytotoxic cutaneous lymphomas often confront the dermatopathologist with intricate diagnostic workup and, moreover, may represent a therapeutic dilemma for the treating dermatologist. We therefore systematically collected all appropriately recorded CD8+ cytotoxic lymphoma infiltrates of the skin being encountered at our institution, spanning a time period of more than 15 years. Our intention was to better characterize such CD8+ lymphoma infiltrates based on histological, immunophenotypical and clinical grounds, and ultimately we tried to provide a better subtype attribution and to delineate putative diagnostic and/or prognostic markers to guide the patient management of this rare lymphoma variant.

\section{METHODS}

Formalin-fixed and paraffin-embedded (FFPE) tissue of patients with EBV-negative cutaneous CD8+ cytotoxic cutaneous T-cell lymphoma infiltrates was retrieved from the archives of the Institute of Pathology, University of Wuerzburg, and the Department of Dermatology, University Hospital Wuerzburg, dating back from 1998 until 2015. Only cases with sufficient analyzable FFPE tissue and corresponding clinical data were included for further analysis. The final diagnosis of lymphoma with subtype assignment was based on a compatible histomorphology, immunophenotype and clonal T-cell receptor gene rearrangement in close correlation with the medical history and clinical presentation according to the current World Health Organization (WHO)/European Organization for Research and Treatment of Cancer (EORTC) classification [1] taking account of the revised WHO proposal [3]. Immunohistochemical studies were performed on FFPE tissue sections using the avidin-biotin-peroxidase complex method and stained in an autostainer in the case of the 
routine antibody panel and manually for selected remaining antibodies, such as PIM1, VEGFR2 and PDGFR $\alpha$. Polymerase chain reaction (PCR) analysis of the TCR- $\gamma$ gene was performed on DNA extracted from FFPE tissue according to the previously published protocol of the Biomed-2 guidelines. Statistical analysis of histological and clinical data was performed with the SPSS software version 22 (IBM GmbH, Germany).

All procedures followed were in accordance with the ethical standards of the responsible committee on human experimentation (institutional and national) and with the Helsinki Declaration of 1964, as revised in 2013. Informed consent was obtained from all patients for being included in the study and for publication of the patient photographs.

\section{RESULTS}

During a 17-year time period, 35 cases could be identified that fulfilled our inclusion criteria; more than 30 cases had to be excluded because of lack of adequate tissue and/or clinical data. Clinicopathological correlation yielded the diagnosis of $\mathrm{MF} / \mathrm{SS}$ in 13 cases, SPTCL in 4 cases, CD8+ acral lymphoma in 5 cases and AECTCL in 1 case. Moreover, 9 out of 35 cases were classified as primary cutaneous PTCL-NOS, while secondary lymphoma infiltrates of the skin due to underlying systemic PTCL-NOS were encountered in 3 cases. Detailed clinical patient characteristics are summarized in Table 1 and histological and immunophenotypic findings in Tables 2 and 3, respectively. Survival data are shown in Fig. 1a.

With respect to CD8+ MF, atypical clinical features mimicking cutaneous mastocytosis or purpura pigmentosa (Fig. 2a) and pityriasis alba (Fig. 2b) commonly diverted the clinician from a prompt initial diagnosis. The corresponding histological pattern was otherwise rather similar to classical CD4+ MF (Fig. 2c,d). Mean overall survival of patients with $\mathrm{CD} 8+\mathrm{MF}$ was 56 months with a corresponding wide range of 12 to 159 months depending on the lymphoma stage. The patients with CD8+ MF showed a clinical course quite similar to otherwise encountered CD4+ variants; one of these patients died because of progressive lymphoma after 12 months.

CD8+ lymphomas $(n=21)$ with deep (dermal or subcutaneous) infiltrates mainly comprised rare and hitherto provisional entities designated as lymphoma subtypes. Five of these cases belonged to the provisional entity of acral CD8+ T-cell lymphoma (ILP) and invariably showed an indolent course with unrestricted survival. The remaining 16 cases exhibited a significantly worse survival and were diagnosed as either primary $(n=9)$ or secondary $(n=3)$ cutaneous PTCL-NOS or as SPTCL $(n=4)$. These patients exhibited a mean overall survival of $51 \pm 66,24 \pm 17$ and $27 \pm 43$ months, respectively. Of this subgroup $5 / 16$ patients died of lymphoma (among these all three patients with secondary PTCL-NOS), whereas an additional 4/16 patients died of other unrelated causes. All 16 of these patients presented with either solitary/regional $(n=8$; Fig. 3a) or multiple $(n=8)$ tumors and/or infiltrated plaques (Fig. 3c). Those patients with a solitary skin lesion of their PTCL-NOS or SPTCL had a trend to better mean overall survival than patients with multiple skin manifestations ( $61 \pm 65$ vs. $21 \pm 23$ months; $P=0.1$ ), albeit exhibiting a wide variation of survival time (Fig. 1b). Solitary manifestation at an acral site (face and finger) represented an independent positive prognostic factor within the patient subgroup of PTCL-NOS with an average overall survival of 112 months. Better 
Table 1 Clinical characteristics of the subtypes of CD8+ cytotoxic lymphomas

\begin{tabular}{|c|c|c|c|c|c|c|c|c|c|c|c|}
\hline & \multicolumn{2}{|l|}{ Age } & \multicolumn{2}{|l|}{ Sex } & \multicolumn{3}{|c|}{ Morphology of lesions } & \multicolumn{2}{|c|}{ Extent of lesions } & \multicolumn{2}{|c|}{$\begin{array}{l}\text { Duration } \\
\text { of lesions } \\
\text { (months) }\end{array}$} \\
\hline & $\overline{\text { Mean }}$ & $\overline{\text { SO }}$ & $\begin{array}{l}\text { Male } \\
n\end{array}$ & $\begin{array}{l}\text { Female } \\
n\end{array}$ & $\begin{array}{l}\text { Patch, } \\
\text { plaque } \\
n\end{array}$ & $\begin{array}{l}\text { Papule, } \\
\text { tumor } \\
n\end{array}$ & $\begin{array}{l}\text { Patch, plaque, } \\
\text { papule, tumor } \\
n\end{array}$ & $\begin{array}{l}\text { Solitary, } \\
\text { localced } \\
n\end{array}$ & $\begin{array}{l}\text { Disseminated } \\
n\end{array}$ & Mean & SO \\
\hline $\begin{array}{l}\text { Mycosis } \\
\text { fungoides }\end{array}$ & 44 & 14 & 8 & 5 & 5 & 2 & 5 & 2 & 11 & 44 & 58 \\
\hline $\begin{array}{c}\text { Cutaneous } \\
\text { PTCL }\end{array}$ & 61 & 11 & 7 & 2 & 1 & 7 & 1 & 8 & 1 & 6 & 11 \\
\hline ILP & 62 & 10 & 2 & 3 & 2 & 3 & 0 & 5 & 0 & 28 & 17 \\
\hline SPTCL & 52 & 6 & 1 & 3 & 0 & 4 & 0 & 0 & 4 & 7 & 5 \\
\hline AECTCL & 26 & & 1 & 0 & 1 & 0 & 0 & 0 & 1 & 3 & \\
\hline $\begin{array}{c}\text { Systemic } \\
\text { PTCL }\end{array}$ & 76 & 12 & 2 & 1 & 1 & 1 & 1 & 1 & 2 & 6 & 6 \\
\hline
\end{tabular}

AECTCL aggressive epidermotropic primary cutaneous T-cell lymphoma, ILP acral CD8+ T-cell lymphoma, formerly indolent CD8+ lymphoid proliferation, PTCL peripheral T-cell lymphoma, SD standard deviation, SPTCL subcutaneous panniculitis-like T-cell lymphoma

survival for patients with solitary skin manifestation at the time of initial presentation was not only observed for this subgroup of deep dermal/subcutanous CD8+ lymphoma infiltrates, but was also true for all studied cases of CD8+ lymphomas: overall survival was $74 \pm 63$ months for patients with localized disease manifestation as compared to $31 \pm 30$ months for patients exhibiting multiple lesions $(P=0.01)$.

In addition to clinical features, we were also interested in thorough histological and immunohistological characterization of our selected CD8+ lymphomas. Histological features and further immunophenotypic characterization are depicted in Tables 2 and 3.

Whereas most of the MF cases showed smalland medium-sized neoplastic cells with rare large-cell transformation and systemic PTCL-NOS showed large neoplastic cells, cell size was otherwise rather evenly distributed among the different entities (Fig. 3b, d). Hence, survival rates were not significantly different between lymphomas with predominantly small- or medium-sized cells and lymphomas with large-cell morphology $(P=0.6)$. Moreover, ulceration, angiocentricity and adnexotropism were a common feature of PTCL-NOS but not of indolent acral CD8+ lymphoma.

With regard to immunohistochemical features, a high proliferation index (ki67 $>60 \%$ ) implied a worse mean overall survival $(P<0.05$; Fig. 4a). Loss of one or several of the T-cell antigens (CD5 and CD7), overexpression of PIM1, PDGFR $\alpha$ or an activated cytotoxic phenotype (positivity of $\mathrm{GrB}$ in conjunction with variable expression of T-cell intracellular antigen-1 [TIA] or perforin; Fig. 4b) were not associated with a more aggressive subtype or a worse clinical course. To note, PIM1 expression was observed with a moderate 

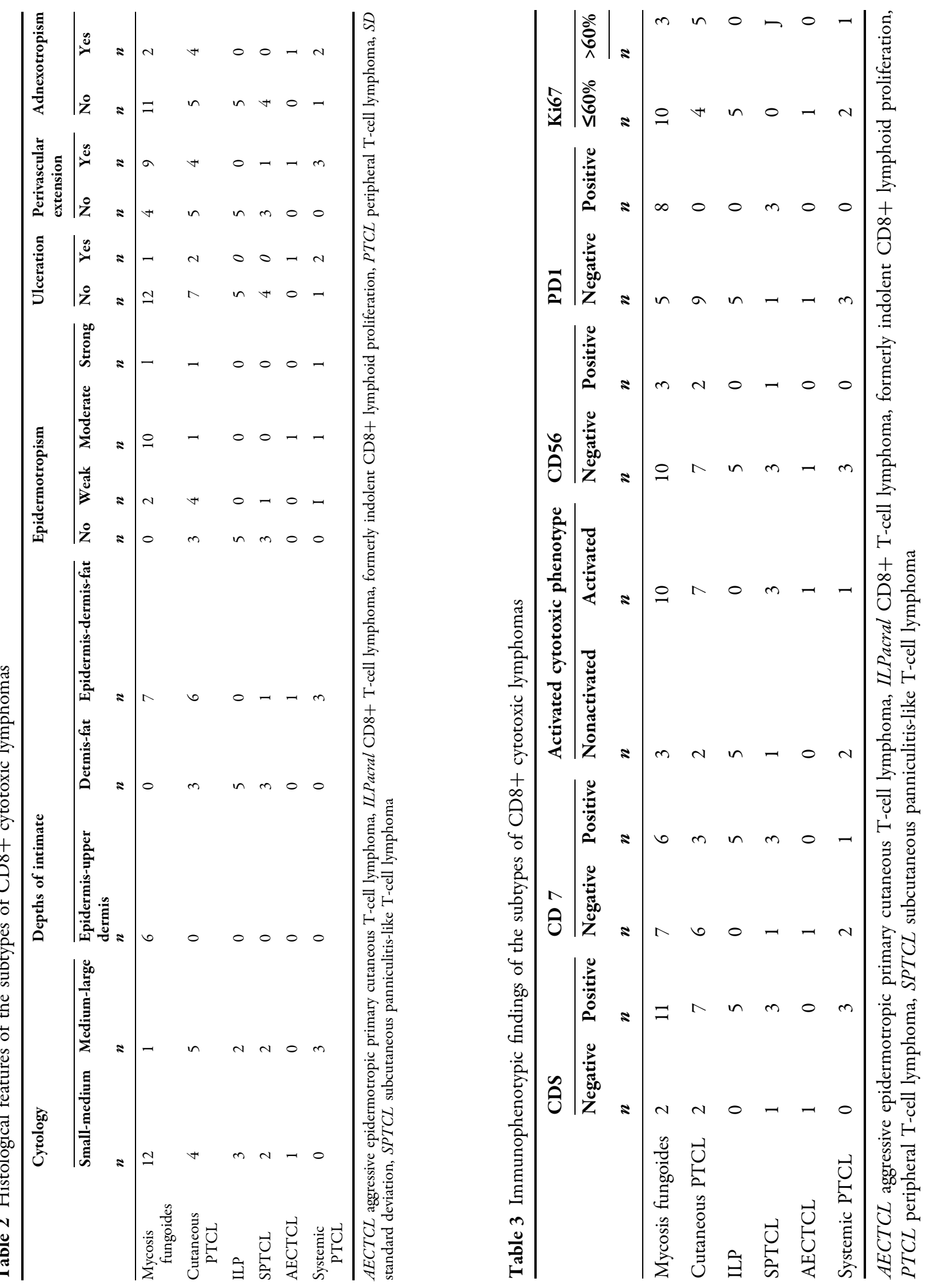


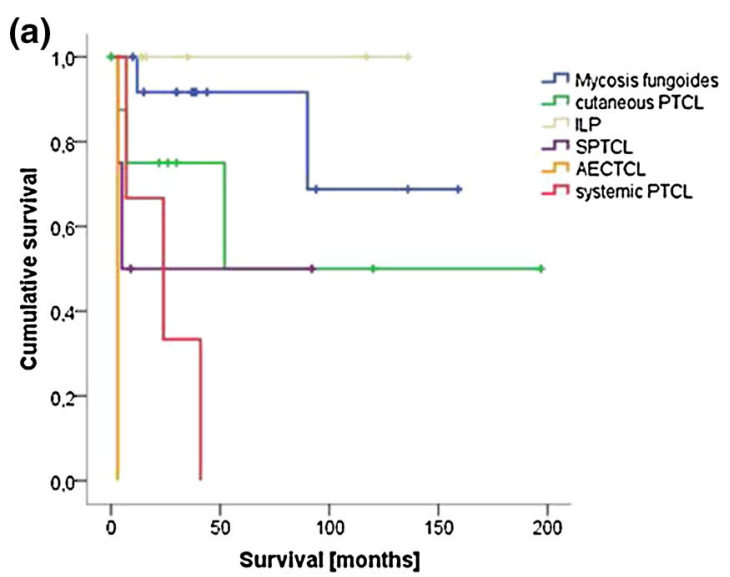

Fig. 1 Overall survival of all analyzed CD8+ lymphoma subtypes and overall survival according to extent of skin lesions. a Overall survival of the different subtypes of CD8+ cytotoxic cutaneous lymphomas shows large heterogeneity with unrestricted survival in ILP up to highly limited survival in AECTL and systemic PTCL-NOS. b Overall survival of patients presenting with solitary/localized skin lesions is significantly higher

to high staining intensity in all the analyaed lymphoma subtypes, whereas only few lymphoma cells expressed PDGFR $\alpha$. None of the lymphomas expressed ALK, EBER, VEGFR2 or Tcl1. There was variable expression of PD1 and CD56. An aberrant expression of immunohistochemical markers by the neoplastic cells was rarely observed: coexpression of CD20 by the neoplastic T-cells of cutaneous PTCL-NOS was detected in one case, and expression of CD68 in a dot-like intracytoplasmic pattern was exclusively observed in lymphoma cells of indolent acral CD8+ lymphoma.

\section{DISCUSSION}

Owing to its versatile clinical and histological presentation, CD8+ cytotoxic cutaneous lymphomas still represent one of the major challenges within the field of dermatology and histopathology. While the current WHO/

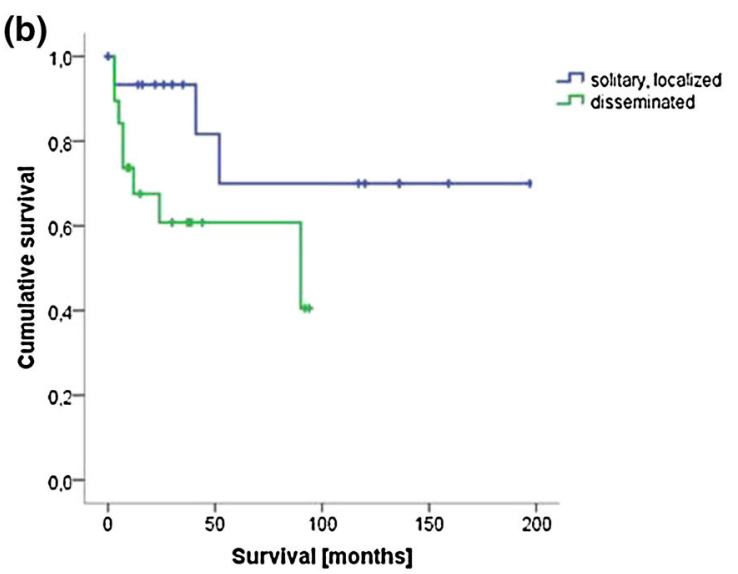

than the overall survival of patients with multiple lesions ( $74 \pm 63$ vs. $31 \pm 30$ months for patients; $P=0.01$ ), albeit showing wide variation. AECTCL aggressive epidermotropic primary cutaneous $\mathrm{T}$-cell lymphoma, ILPacral CD8+ T-cell lymphoma, formerly indolent CD8+ lymphoid proliferation, NOS not otherwise specified, PTCL peripheral T-cell lymphoma, SPTCL subcutaneous panniculitis-like T-cell lymphoma

EORTC classification does not allow further subdivision within this lymphoma subgroup based on criteria such as the extent and localization of skin lesions, cell size or T-cell phenotype, and comprehensive molecular features, including gene expression data or mutation profiles are still lacking, a plethora of clinical and histopathological features has up to now been collected and proposed to portend a putative prognostic impact. These include cytomorphology (small versus large cells), immunophenotype (loss or presence of T-cell antigens: CD2, CD5 and CD7 [6, 7]), expression of $\mathrm{T}$-cell receptor $\alpha / \beta$-chains versus T-cell receptor $\gamma / \mathrm{d}$-chains [8], expression of cytotoxic proteins [perforin, granzyme B (GrB), T-cell intracellular antigen (TIA)] [9], proliferative activity (ki67) [9]), architectural features of the infiltrate (epidermotropism, depth of infiltrate and angioinvasion) and clinical presentation [solitary versus multiple lesions corresponding to tumor stage according to the EORTC-/ 

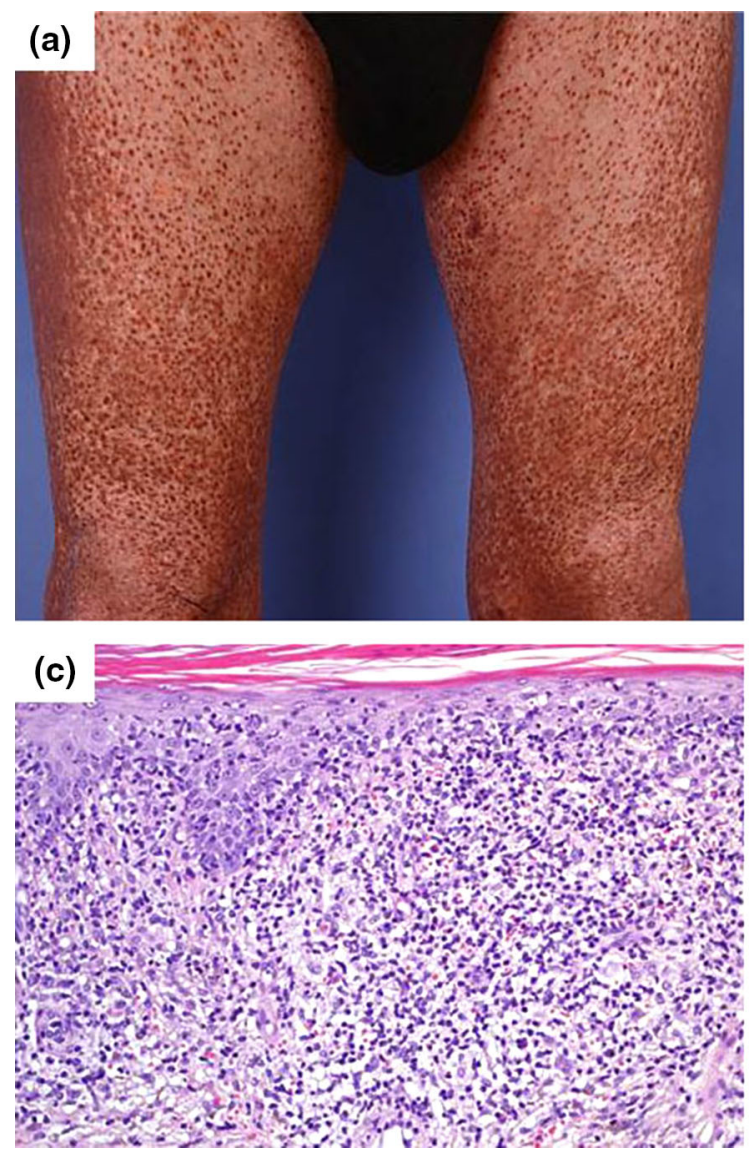

Fig. 2 Selected clinical and histological examples of atypical presentation of CD8+ MF cases. CD8+ cytotoxic MF frequently exhibits atypical clinical presentation mimicking mastocytosis (urticaria pigmentosa) $\mathbf{a}$ in the case of hyperpigmented and purpuric MF or pityriasis alba/vitiligo and $\mathbf{b}$ in hypopigmented juvenile MF. c Histology of case (a) shows an atypical band-like

ISCL-classification (TNM) or the International Prognostic Index (IPI)/Peripheral T-cell Lymphoma Index (PTI) score].

While in our analysis most of the cases of MF presented with small lymphoma cells, large tumor cells with partly blast-like morphology were prevailing in both primary cutaneous and secondary cutaneous PTCL-NOS. With respect to MF, large-cell transformation has been established as an independent negative prognostic factor, irrespective of age, tumor stage and IPI score and independent of (b)
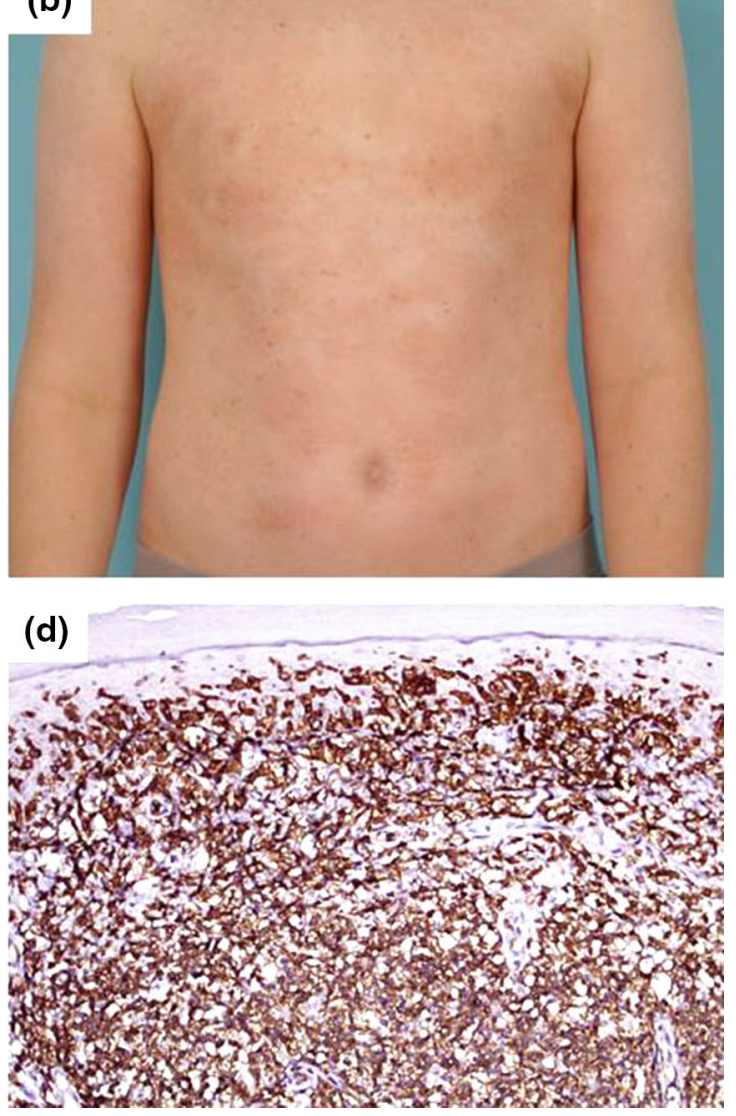

infiltrate of pleomorphic small-/medium-sized lymphocytes with frank epidermotropism in a pagetoid pattern together with interface dermatitis, dermal erythrocytes, melanophages and hemosiderophages. Dermal and epidermal lymphoma cells of case (a) strongly express CD8 (d) and cytotoxic molecules. $M F$ mycosis fungoides

concomitant CD30 expression [10]. In one of the largest recent studies addressing the predictive impact of cytology in 82 patients with cutaneous cytotoxic PTCL-NOS, small-/ medium-sized cell type turned out to have prognostic impact [11]. However, divergent from our approach, both CD4+ and CD8+ PTCL-NOS presenting with a cytotoxic phenotype were included in this analysis, and the favorable subgroup of small-/medium-sized lymphomas was mainly attributed to CD4+ small-/medium-sized pleomorphic T-cell 

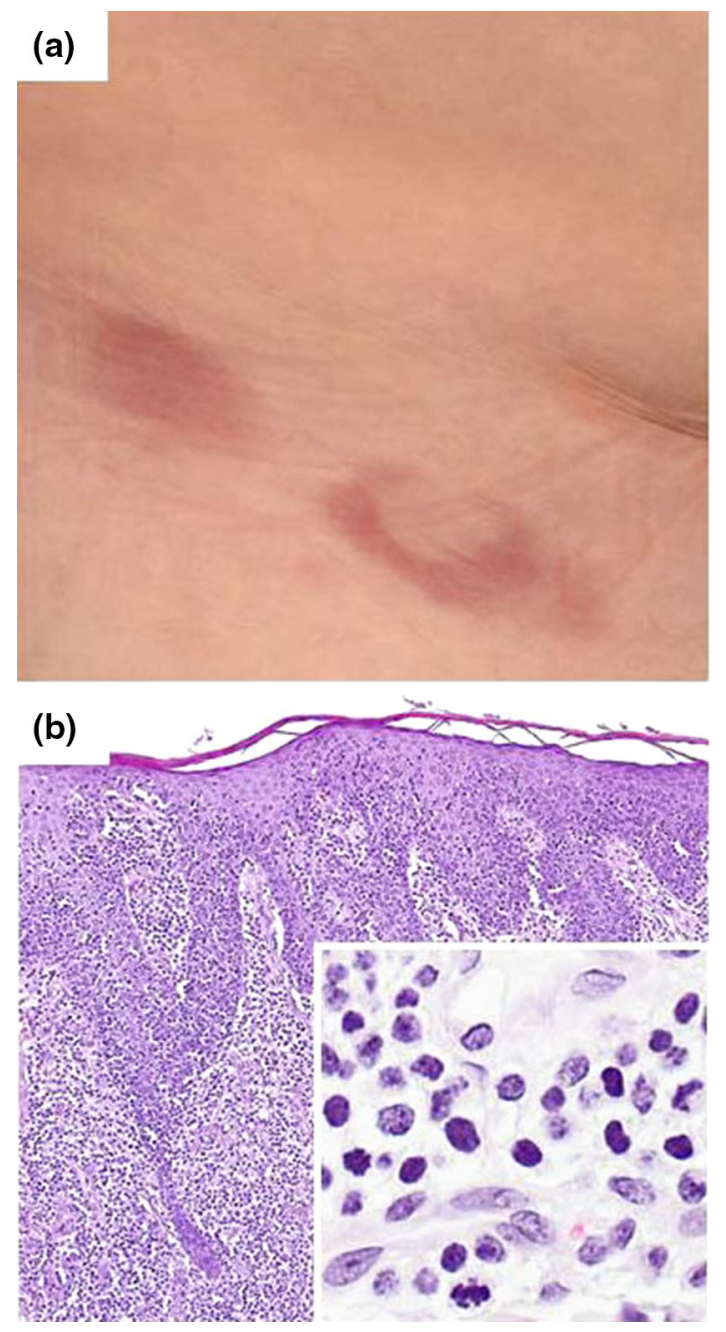

Fig. 3 Representative clinical and histological examples of cutaneous PTCL-NOS. Localized skin lesions at time of diagnosis of primary cutaneous PTCL-NOS a exhibiting a highly epidermotropic lymphoma infiltrate of highly proliferating pleomorphic small-/medium-sized lymphoma cells (b). c Multiple disseminated non-ulcerated patches,

lymphoma (SMPTCL) with a well-known indolent behavior [12].

Extent of skin lesions is one of the major categories within the IPI for predicting the biological behavior of systemic PTCL and accordingly directing further therapeutic approaches [11]. Solitary skin lesions were attributed to a longer overall survival in our 35 cases of CD8+ cytotoxic lymphomas.
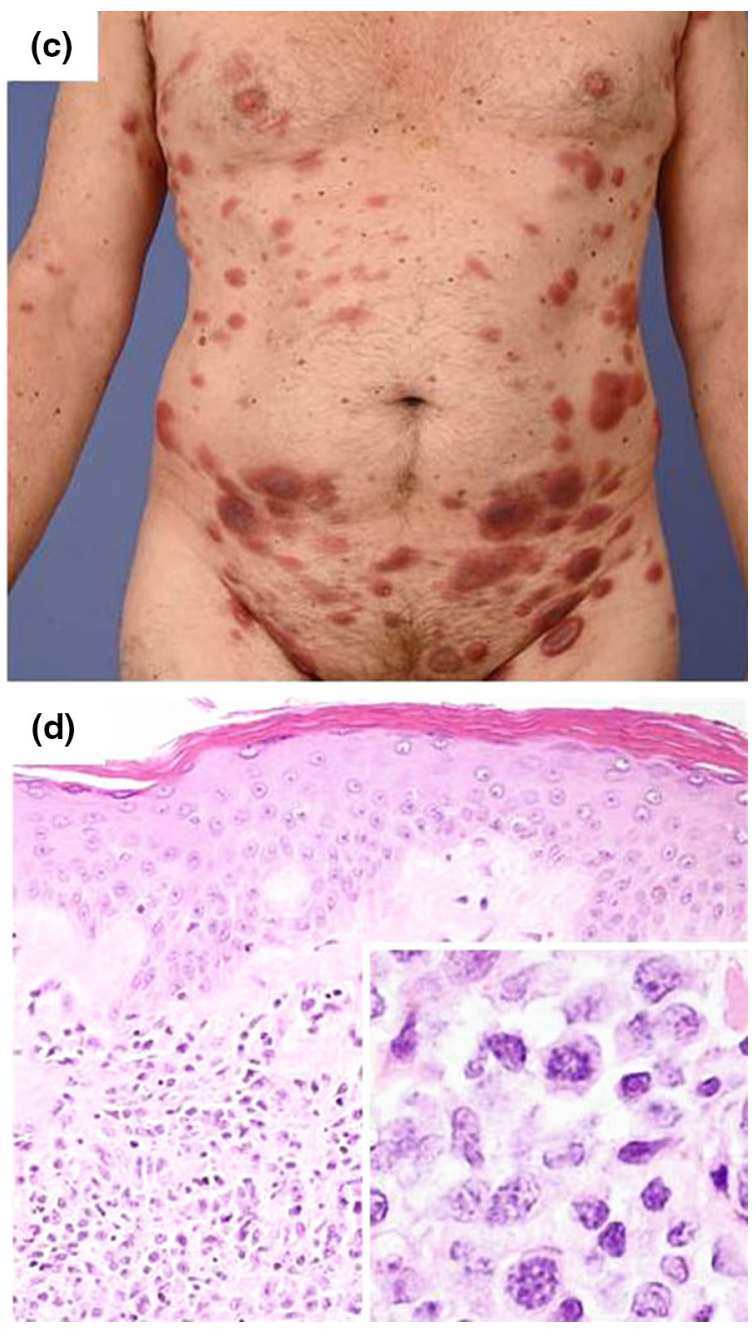

plaques and flat tumors at the trunk and extremities are present in this patient with cutaneous PTCL-NOS. d Histology shows blast-like large dermal tumor cells with multiple mitotic figures. PTCL-NOS peripheral T-cell lymphoma, not otherwise specified

A recent study highlighted the negative prognostic impact of both $\gamma / \mathrm{d}$-T-cell receptor expression (Vd1 subset) and deep subcutaneous involvement in cutaneous T-cell lymphoma [11]. However, rare expression of $\gamma / \mathrm{d}$-T-cell receptor chains may also be observed in $\mathrm{CD} 4+$ or CD8+ cutaneous lymphomas, such as MF, anaplastic large-cell lymphoma or pagetoid reticulosis, and these lymphomas run a rather 


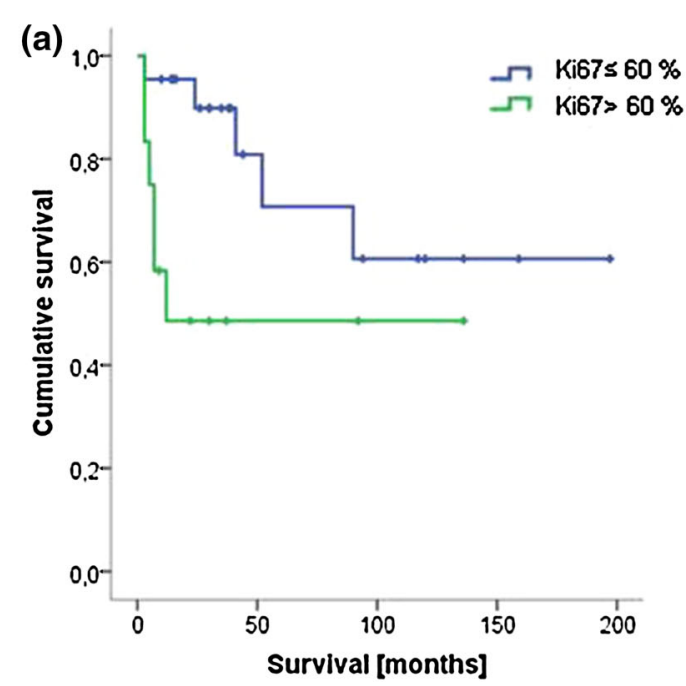

Fig. 4 Overall survival with respect to proliferation rate and cytotoxic phenotype. a Overall survival for patients showing a high proliferation rate as assessed by $>60 \%$ ki67-positive lymphoma cells is significantly lower than

indolent or stage-dependent course [13]. In less than $1 \%$ of cases, lineage infidelity with, e.g., aberrant expression of CD20 or concomitant dual expression of both $\gamma / \mathrm{d}$-chains and $\alpha \beta$-chains of the T-cell receptor [14] may be observed, as was present in one case of cutaneous PTCL-NOS in our study.

With regard to T-cell antigen expression, it has been initially postulated that loss of several T-cell markers, such as CD2 and CD5, could serve as a diagnostic clue for AECTCL and thus portend a worse prognosis [6, 7]. However, more recent studies, including ours, showed more variable and inconsistent expression (or loss) of the T-cell antigens CD2, CD5 and CD7 [15], so these immunophenotypic features do not serve as helpful diagnostic adjuncts.

Several studies on systemic CD8+ (and CD4+) PTCL-NOS have already addressed the question whether an activated cytotoxic phenotype might represent an adverse prognostic factor. Most of the studies, including a large recent analysis of 340 patients with CD4+ and CD8+ PTCL-NOS,

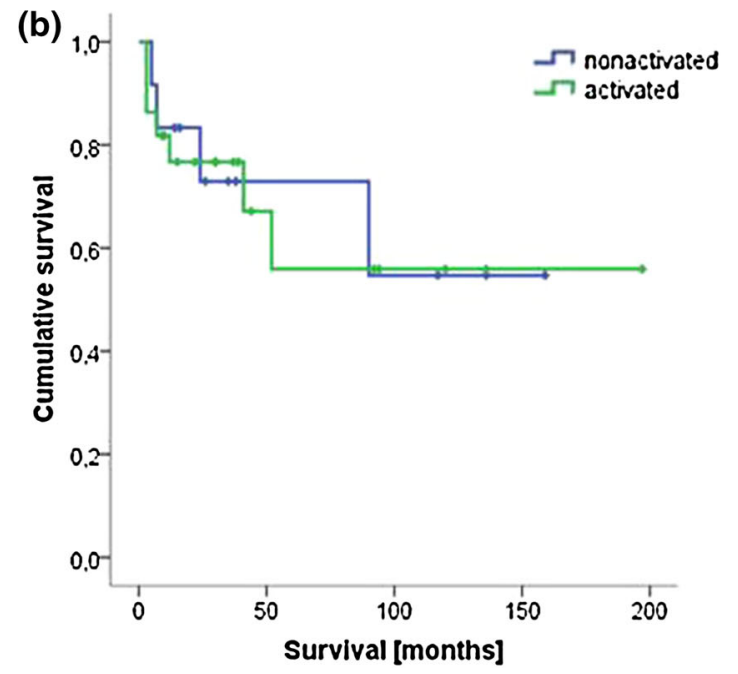

low-proliferating tumors $(P<0.05)$. b Presence of an activated cytotoxic phenotype [positivity of $\mathrm{GrB}$ together with perforin and/or T-cell intracellular antigen (TIA)] does not affect overall survival

being analyzed within the International Peripheral T-cell Lymphoma Project could not confirm a negative prognostic impact thereof $[9,16,17]$. However, a subgroup of PTCL-NOS with molecular features of cytotoxic lymphocytes exhibiting overexpression of TBX21 while being negative for GATA3 was recently identified to portend a worse prognosis [18]. In our analysis on cutaneous lymphomas, an activated cytotoxic phenotype did not harbor any prognostic impact. Of note, being in line with most of the previously reported results in systemic PTCL-NOS [19], a high proliferation index (ki67 $>60 \%)$ indicated a worse survival in our cohort. On the other hand, we have recently shown that low proliferative capacity together with an exclusive expression of CD68 in a particular dot-like pattern in the lymphoma cells represents a unique hallmark of primary cutaneous acral CD8+ T-cell lymphoma and thus presents an indolent behavior when present [20]. 
With the aim to gain further insight into the pathogenesis and the biological behavior of rare cutaneous lymphomas, such as CD8+ cytotoxic lymphomas, much can be learned and transferred from recent work on molecular profiling of systemic PTCL-NOS, including gene expression and deep sequencing analysis $[19,21,22]$. Gene expression profiling has once again confirmed that within the generic term of systemic PTCL-NOS, there is extensive molecular heterogeneity as already evidenced by divergent clinical, histological and immunophenotypical data [18, 23, 24]. Moreover, taking the limited therapeutic opportunities and the often dismal prognosis of PTCL-NOS into consideration, the progress in deciphering the mutational landscape and the subtype-specific gene expression profiles has revealed several novel therapeutic options [25]. Putative targets include the network of epigenetic modifiers [26] as well as the NFкB, STAT and JAK pathways [27], PIM kinases [27] and downstream signaling of tyrosine receptors, such as PDGFR $\alpha$ [28] and VEGFR [29]. In the lymphoma cases presented here, the expression pattern of PIM1 (which was actually present in almost all cases), VEGFR or PDGFR $\alpha$ (which were almost altogether absent in our cohort) did not serve as putative prognostic markers, so that these data could not be recapitulated in our CD8+ cutaneous lymphoma cohort.

\section{CONCLUSIONS}

Our retrospective analysis once again underlines that when dealing with CD8+ cutaneous lymphoma, the crucial approach still remains to unify the histological and clinical data to make a correct diagnosis with prognostically relevant subtype attribution as long as better immunophenotypical and especially genetic data are still lacking. In the future, molecular profiling of such rare lymphoma variants will hopefully contribute to ameliorate treatment strategies as a result of more precise subtype definition and to develop more individualized treatment strategies, including targeted therapies. As cutaneous CD8+ lymphomas represent rare entities and our study data are therefore limited in its conclusions, a broader multi-institutional approach for these lymphoma entities is urgently warranted in the future.

\section{ACKNOWLEDGMENTS}

No funding or sponsorship was received for this study or publication of this article. All named authors meet the International Committee of Medical Journal Editors (ICMJE) criteria for authorship for this manuscript, take responsibility for the integrity of the work as a whole and have given final approval for the version to be published.

Disclosures. Marion Wobser, Theresa Reinartz, Sabine Roth, Matthias Goebeler, Andreas Rosenwald and Eva Geissinger have nothing to disclose.

Compliance with Ethics Guidelines. All procedures followed were in accordance with the ethical standards of the responsible committee on human experimentation (institutional and national) and with the Helsinki Declaration of 1964, as revised in 2013. Informed consent was obtained from all patients for being included in the study and for publication of the patient photographs.

Open Access. This article is distributed under the terms of the Creative Commons Attribution-NonCommercial 4.0 International 
License (http://creativecommons.org/licenses/ by-nc/4.0/), which permits any noncommercial use, distribution, and reproduction in any medium, provided you give appropriate credit to the original author(s) and the source, provide a link to the Creative Commons license, and indicate if changes were made.

\section{REFERENCES}

1. Willemze R, Jaffe ES, Burg G, Cerroni L, Berti E, Swerdlow SH, et al. WHO-EORTC classification for cutaneous lymphomas. Blood. 2005;105:3768-85.

2. Lu D, Patel KA, Duvic M, Jones D. Clinical and pathological spectrum of CD8-positive cutaneous T-cell lymphomas. J Cutan Pathol. 2002;29:465-72.

3. Swerdlow SH, Campo E, Pileri SA, Harris NL, Stein $\mathrm{H}$, Siebert R, et al. The 2016 revision of the World Health Organization classification of lymphoid neoplasms. Blood. 2016;127:2375-90.

4. Petrella $\mathrm{T}$, Maubec E, Cornillet-Lefebvre $\mathrm{P}$, Willemze R, Pluot M, Durlach A, et al. Indolent CD8-positive lymphoid proliferation of the ear: a distinct primary cutaneous T-cell lymphoma? Am J Surg Pathol. 2007;31:1887-92.

5. Gormley RH, Hess SD, Anand D, Junkins-Hopkins J, Rook AH, Kim EJ. Primary cutaneous aggressive epidermotropic CD8+ T-cell lymphoma. J Am Acad Dermatol. 2010;62:300-7.

6. Berti E, Tomasini D, Vermeer MH, Meijer CJ, Alessi E, Willemze R. Primary cutaneous CD8-positive epidermotropic cytotoxic $\mathrm{T}$ cell lymphomas. A distinct clinicopathological entity with an aggressive clinical behavior. Am J Pathol. 1999;155:483-92.

7. Agnarsson BA, Vonderheid EC, Kadin ME. Cutaneous $\mathrm{T}$ cell lymphoma with suppressor/cytotoxic (CD8) phenotype: identification of rapidly progressive and chronic subtypes. J Am Acad Dermatol. 1990;22:569-77.

8. Toro JR, Liewehr DJ, Pabby N, Sorbara L, Raffeld M, Steinberg SM, et al. Gamma-delta T-cell phenotype is associated with significantly decreased survival in cutaneous T-cell lymphoma. Blood. 2003;101:3407-12.
9. Weisenburger DD, Savage KJ, Harris NL, Gascoyne RD, Jaffe ES, MacLennan KA, et al. Peripheral T-cell lymphoma, not otherwise specified: a report of 340 cases from the International Peripheral T-cell Lymphoma Project. Blood. 2011;117:3402-8.

10. Scarisbrick JJ, Prince HM, Vermeer MH, Quaglino P, Horwitz S, Porcu P, et al. cutaneous lymphoma international consortium study of outcome in advanced stages of mycosis Fungoides and Sézary Syndrome: effect of specific prognostic markers on survival and development of a prognostic model. Oncol: J Clin Oncol Off J Am Soc Clin; 2015.

11. Bekkenk MW, Vermeer MH, Jansen PM, van Marion AMW, Canninga-van Dijk MR, Kluin PM, et al. Peripheral T-cell lymphomas unspecified presenting in the skin: analysis of prognostic factors in a group of 82 patients. Blood. 2003;102:2213-9.

12. Beltraminelli H, Leinweber B, Kerl H, Cerroni L. Primary cutaneous CD4+ small-/medium-sized pleomorphic T-cell lymphoma: a cutaneous nodular proliferation of pleomorphic $T$ lymphocytes of undetermined significance? A study of 136 cases. Am J Dermatopathol. 2009;31:317-22.

13. Rodríguez-Pinilla SM, Ortiz-Romero PL, Monsalvez V, Tomás IE, Almagro M, Sevilla A, et al. TCR- $\gamma$ expression in primary cutaneous T-cell lymphomas. Am J Surg Pathol. 2013;37:375-84.

14. Tomasini D, Niccoli A, Crivelli F. Pagetoid reticulosis tumor cells with double expression of TCR $\gamma \delta$ and TCR $\alpha \beta$ : an off-target phenomenon or genuine expression? J Cutan Pathol. 2015;42:427-34.

15. Robson A, Assaf C, Bagot M, Burg G, Calonje J, Castillo C, et al. Aggressive epidermotropic cutaneous CD8+ Lymphoma: a cutaneous lymphoma with distinct clinical and pathological features Report of an EORTC Cutaneous Lymphoma Task Force Workshop. Histopathology. 2014.

16. Went P, Agostinelli C, Gallamini A, Piccaluga PP, Ascani S, Sabattini E, et al. Marker expression in peripheral T-cell lymphoma: a proposed clinical-pathologic prognostic score. J Clin Oncol Off J Am Soc Clin Oncol. 2006;24:2472-9.

17. Geissinger E, Odenwald T, Lee S-S, Bonzheim I, Roth S, Reimer P, et al. Nodal peripheral T-cell lymphomas and in particular, their lymphoepithelioid (Lennert's) variant are often derived from CD8(+) cytotoxic T-cells. Virchows Arch Int J Pathol. 2004;445:334-43. 
18. Iqbal J, Wright G, Wang C, Rosenwald A, Gascoyne $\mathrm{RD}$, Weisenburger $\mathrm{DD}$, et al. Gene expression signatures delineate biological and prognostic subgroups in peripheral T-cell lymphoma. Blood. 2014;123:2915-23.

19. Costello R, Sanchez C, Le Treut T, Rihet P, Imbert J, Sébahoun G. Peripheral T-cell lymphoma gene expression profiling and potential therapeutic exploitations. Br J Haematol. 2010;150:21-7.

20. Wobser M, Roth S, Reinartz T, Rosenwald A, Goebeler M, Geissinger E. CD68 expression is a discriminative feature of indolent cutaneous CD8-positive lymphoid proliferation and distinguishes this lymphoma subtype from other CD8-positive cutaneous lymphomas. Br J Dermatol. 2015;172:1573-80.

21. Gaulard P, de Leval L. Pathology of peripheral T-cell lymphomas: where do we stand? Semin Hematol. 2014;51:5-16.

22. Vose J, Armitage J, Weisenburger D. International T-Cell lymphoma project. International peripheral T-cell and natural killer/T-cell lymphoma study: pathology findings and clinical outcomes. J Clin Oncol Off J Am Soc Clin Oncol. 2008;26:4124-30.

23. Couronné L, Bastard C, Gaulard P, Hermine O, Bernard O. Molecular pathogenesis of peripheral T-cell lymphoma (1): angioimmunoblastic T-cell lymphoma, peripheral T-cell lymphoma, not otherwise specified and anaplastic large cell lymphoma. Médecine Sci MS. 2015;31:841-52.

24. Gaulard P, de Leval LVIII. New markers in peripheral T-cell lymphomas: more entities or more confusion? Hematol Oncol. 2013;31(Suppl 1):51-6.

25. Iqbal J, Wilcox R, Naushad H, Rohr J, Heavican TB, Wang C, et al. Genomic signatures in T-cell lymphoma: How can these improve precision in diagnosis and inform prognosis? Blood Rev. 2015.

26. Lemonnier F, Couronné L, Parrens M, Jaïs J-P, Travert M, Lamant $\mathrm{L}$, et al. Recurrent TET2 mutations in peripheral T-cell lymphomas correlate with TFH-like features and adverse clinical parameters. Blood. 2012;120:1466-9.

27. Martinez-Delgado $B$, Meléndez $B$, Cuadros $M$, Alvarez J, Castrillo JM, Ruiz De La Parte A, et al. Expression profiling of T-cell lymphomas differentiates peripheral and lymphoblastic lymphomas and defines survival related genes. Clin Cancer Res Off J Am Assoc Cancer Res. 2004;10:4971-82.

28. Piccaluga PP, Agostinelli C, Califano A, Rossi M, Basso K, Zupo S, et al. Gene expression analysis of peripheral $\mathrm{T}$ cell lymphoma, unspecified, reveals distinct profiles and new potential therapeutic targets. J Clin Invest. 2007;117:823-34.

29. Jørgensen JM, Sørensen FB, Bendix K, Nielsen JL, Funder A, Karkkainen MJ, et al. Expression level, tissue distribution pattern, and prognostic impact of vascular endothelial growth factors VEGF and VEGF-C and their receptors Flt-1, KDR, and Flt-4 in different subtypes of non-Hodgkin lymphomas. Leuk Lymphoma. 2009;50:1647-60. 